\title{
Design and Development of Portable Solar Parabolic Cooker with Inorganic PCM Storage
}

\author{
L. Chitra, S. Prakash, Anand M, Jeffin Mathew, Darwin Varghese
}

\begin{abstract}
This paper, an experimental investigation is carried on a solar cooker with heat storage. Solar cookers are passive solar devices, which converts sunlight into to heat energy which is retained for boiling. Solar boilers use the cinch principle of mirror image application, green house effect and absorption to convert sunlight to heat energy. The steps involved in the solar boiler concentrating capturing and converting the PV energy. It is a clean cooking technology without any carbon emission. The main challenges of solar cooker are economically not viable, incompatible with traditional cooking, direct sun cooking, off solar boiling, risk of getting parched. The PCM material used here is $\mathrm{Mg}(\mathrm{NO3}) 2.6 \mathrm{H} 20$. The mentioned challenges have been resolved in proposed design.
\end{abstract} solar cooker, Phase change material.

\section{INTRODUCTION}

Solar energy is safe, healthy for the environment and therefore it is known as alternative energy resources options. Therefore, solar cooker gives a simple and prefect way for utilizing the PV power. Various classification and design for solar cooker. For different development various accomplishment attributes will be utilized. Basically solar cookers are mainly classified into two groups. The first group is solar cooker with storage and other one is solar cookers without storage [1].

Solar boilers are listed as direct and indirect solar boilers without storage by which a common mechanism called heat transfer [2]. In direct type solar cookers, solar emission is used for the baking purposes, while, in the indirect method thermal convection fluid is used to shift the heat to the vessel [3]. The enormous potential of Solar energy can be used to produce electric power, heating and cooling purpose drying agriculture products, desalination of sea water and boiling etc. solar thermal power conversion is one of the solar energy conversion technologies to meet the above mentioned needs in the human daily life in developing countries, from the total energy consumption, noticeable energy is consuming for cooking application throughout the year. Energy demand for the cooking application was met by wood in rural area [4].

Revised Manuscript Received on December 30, 2019.

Dr. L. Chitra*, Associate Professor, Department of Electrical and Electronics Engineering, Aarupadai Veedu Institute of Technology, Chennai, Tamil Nadu, India.

S. Prakash, Assistant Professor, Department of Electrical and Electronics Engineering, Aarupadai Veedu Institute of Technology, Vinayaka Mission's Research Foundation, Chennai, Tamil Nadu, India.

Anand .M, Jeffin Mathew, Darwin Varghese, UG Students, Department of Electrical and Electronics Engineering, Aarupadai Veedu Institute of Technology, Chennai, Tamil Nadu, India.
Keywords: Efficiency, Heat transfer Heat storage, Portable

Because of their high energy storage capacity, PCMs are likely applicants for analysis as thermal depository media. A small PCM storage system can be used to quickly supply the object with a greater sum of thermal. Hence, PCM is a better case for storing solar energy during daylight medium and can be used for late-night or off sunshine cooking. The bottom of the plan; as The primary degree increases, ions break up within the PCM as the material changes from solid to liquid phase. The phase change is a heat-seeking (endothermic) mechanism and therefore heat is absorbed by the PCM. When heat is stored in the depository particle, the particle commences to disintegrate when the degree achieved [5]. The degree remains fixed until the function of melting is complete. The thermal accumulated during disintegrating process is called latent heat. Latent heat storage is characterized by an increased power density. During the cyclical melting and freezing of a PCM, different types of heat transfer were discussed [6]. Due to the decreased weight and volume, power storage in PCM has many advantages over sensitive systems. At consistent degree the power stored and the loss of power in atmosphere is decreased in traditional structure. Paraffin waxes are degrading and have a balanced volume of TES but lesser heat conductivity and thus require a large surface area [7]. Hydrated salts have a higher density of energy storage and thermal conductivity. The depository of heat power in the form of responsive thermal and inherent thermal has become an important condition of power management, with focus not only on the effective use and of solar energy and deceased heat in manufacturing and construction but also for solar boiling. [8-10].

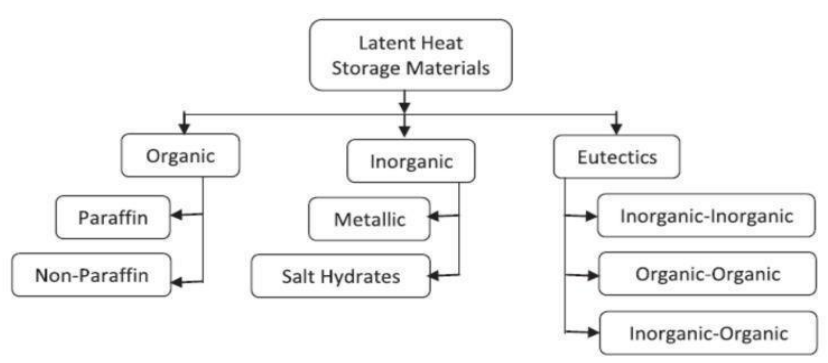

Fig. 1. Types of inherent heat

\section{MATERIALS AND METHODS}

The handy figurative solar cooker with PCM depository technology is basically a parabolic solar cooker. To make the usage of existing parabolic solar cookers more effective and efficient, PCM storage technology is incorporated in the cooking pot.

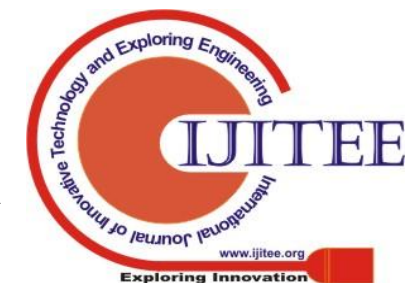


The conventional parabolic collector will be modified such as a compact parabolic collector which reflects the solar radiation to the boiling pot placed at the center. A coaxial double layered boiling pot was fixed at the center of the parabolic collector. The gap between two layers of cooking pot will be filled with the specific PCM for heat storage during sun shine hours. $\mathrm{Mg}(\mathrm{NO} 3) 2.6 \mathrm{H} 2 \mathrm{O}$, an Inorganic salt hydrate PCM used as a storage medium in this invention [11].

During daylight, the solar cooker can be placed in sunshine by and the boiling pot will be fixed at the center. Solar energy falls on the parabolic collector will be reflected to the boiling pot and the charging process of the PCM in cooking pot layer will be initiated. The food materials can be cooked in the cooking pot during sunshine hours efficiently with the direct heat reflected from the parabolic collector and the heat stored in the PCM. These two heat components reduce the time taken for cooking. After charging process of the PCM during sunshine hours, the cooking pot can be placed in insulation box for the off sunshine cooking process. After sunshine hours, discharging process of the PCM will be initiated, where the heat retained will be used for the off sunshine cooking process [12-13]. The amount of heat stored in the PCM is sufficient to cook one batch of food materials during off sunshine hours. The compact structure of the collector will make the collector to be a portable solar collector. This feature of the cooker, protects the solar collector from bad environment conditions and easy to carry the complete system from one place to another place. The required major components and their specifications for handy figurative solar boiler with PCM depository technology are mentioned below.

- Parabolic collector material -3M Reflective film

- Base parabolic concentrator - Aluminum sheet

- Cooking pot - Aluminum or stainless steel coaxial cylindrical.

- PCM - Inorganic salt hydrate PCM Mg (NO3)2.6H2O

- Insulation box - Poly Urethane foam sheet

Fig.2, represents the geometrical design of the solar are about $52 \mathrm{~cm}$ and $13 \mathrm{~cm}$. Focal length of the dish from the bottom of the solar concentrator is about $45 \mathrm{~cm}$.

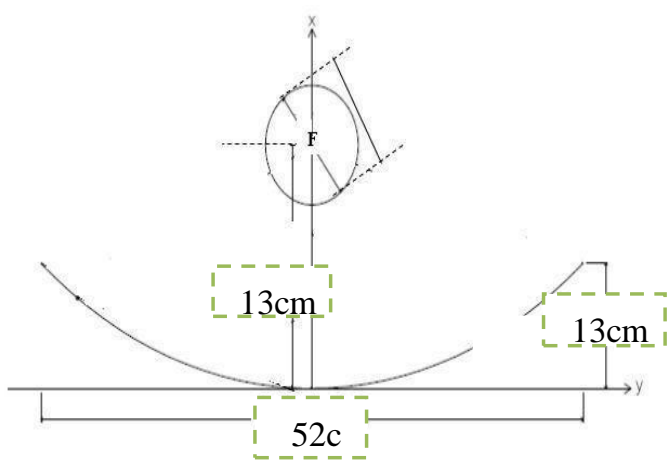

Fig. 2. Geometric representation of the system

Fig. 3 represents the schematic view of the boiling pot of the solar parabolic boiler. The receiver is a two layered parabolic concentrator. The diameter and height of the dish

coaxial cylindrical container with gap between the layers is about $1 \mathrm{~cm}$. The gap between the two layers will be filled with the $\mathrm{PCM} \mathrm{Mg}(\mathrm{NO} 3) 2.6 \mathrm{H} 2 \mathrm{O}$ upto the vent of the receiver.

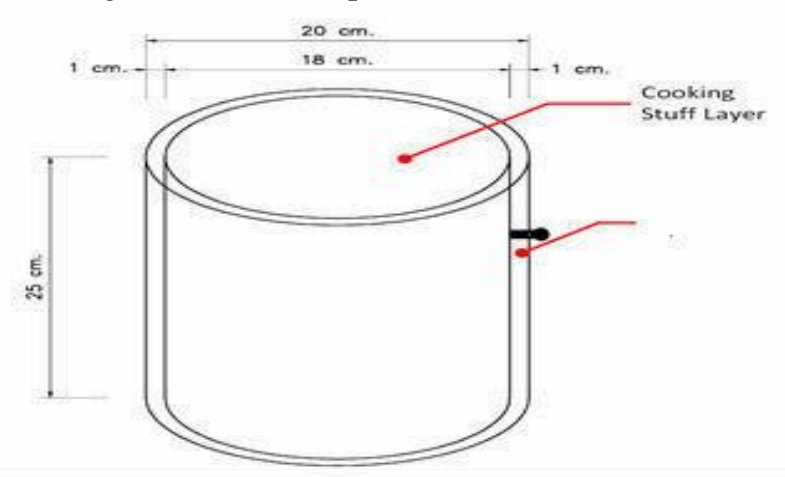

Fig. 3. Schematic view of cooking pot

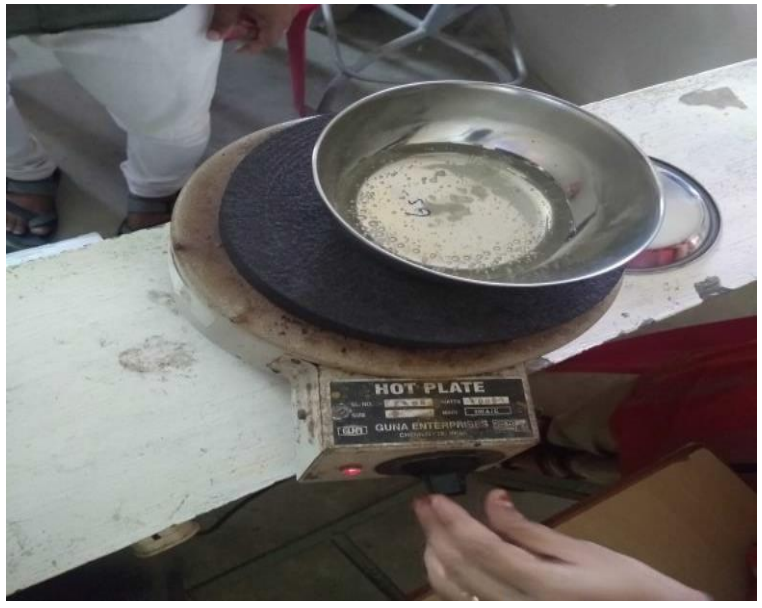

Fig. 4. Thermal cycling process of PCM

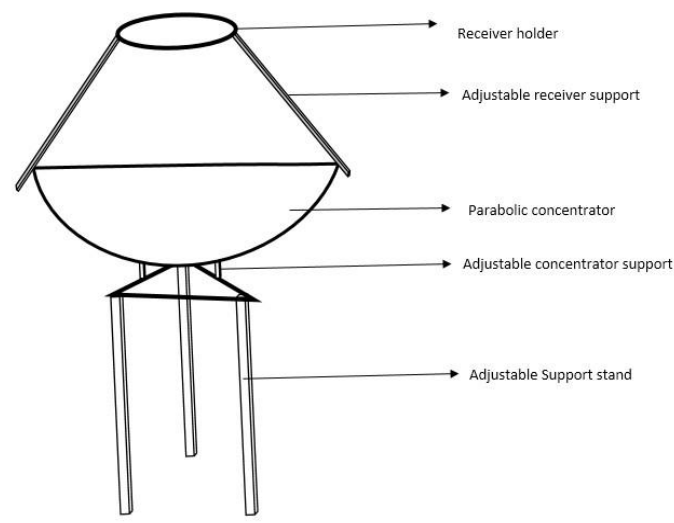

Fig. 5. Schematic view of complete system

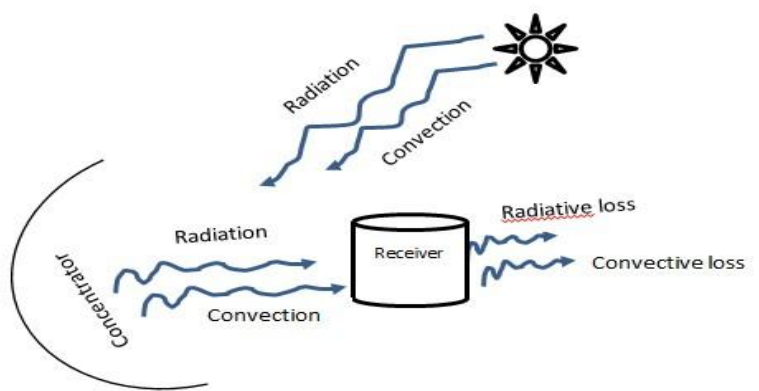

Fig. 6. Schematic view of heat transfer mechanism 
Fig. 6, represents the heat transfer mechanism of the designed solar cooker. The heat gain to the parabolic cooker and heat losses from the parabolic dish and receiver are mentioned in the figure.

\section{MATHEMATICAL CALCULATIONS FOR SOLAR CONCENTRATOR AND RECEIVER}

The ' $\mathrm{f}$ ' is denoted as focal length of solar concentrator [11]

$t=\frac{\eta^{2}}{16 h}$

$\phi \equiv 2 \tan ^{-1}\left[\frac{D}{4 f}\right]$

Acceptance angle,

$\phi_{A}-\frac{90-\phi}{2}$

Concentration ratio,

$\theta=\frac{1}{\sin ^{2} \phi}$

The peak radius of the concentrator,

$P=\frac{2 f}{1+\cos \phi}$

Surface area of the parabolic concentrator is the outer area of the parabolic concentrator,

$A_{s}=\frac{8 \Pi f^{2}}{3}\left\{\left[\left(\frac{D^{2}}{4 f}\right)+1\right]^{\frac{3}{2}}-1\right\}$

Aperture area,

$A_{a}=\frac{\Pi}{4}(2 P \sin \phi)^{2}$

Diameter of the focal length,

$D_{f o}=2 P \sin \theta_{\mathrm{A}}$

Area of focal point,

$A_{f}=\frac{\Pi}{4 f_{0}}(D)^{2}$

Area of the boiling pot is calculated using expression

$A_{r}=2 \pi_{p}\left(r_{p}+h_{p}\right)$

Complete efficiency [12],

$Q_{\text {in }}=I \eta_{0}\left(A_{p}+A_{c}\right) \Delta t$

Where $\mathrm{I}=$ solar irradiation, $\mathrm{W} / \mathrm{m}^{2}$

$\eta_{0}=$ Optical efficiency of solar concentrator $\mathrm{A}_{p}$

$=$ aperture area concentrator, $\mathrm{m}$

$\mathrm{A}_{c}=$ area of cooking pot $\mathrm{r}$ receiver, $\mathrm{m}$

$\Delta t=$ time, sec

Efficiency of the solar cooker without storage,

\section{RESULTS AND COMPUTERIZED CLEANING SYSTEM OPERATION}

The design and development and evaluation of the
$\mathrm{Mg}(\mathrm{NO} 3) 2.6 \mathrm{H} 2 \mathrm{O}$ phase change material storage system for solar cooking application was performed in department of electrical and electronics engineering, AVIT, Chennai.

The latitude and longitude of the place are $13.027 \mathrm{o} \mathrm{N}$, $80.2707 \mathrm{o}$ E respectively and the average solar radiation of the place is about $605 \mathrm{~W} / \mathrm{m} 2$. The efficiency experiment of the system is calculated by conducting the experiment for a week days during March 2019. From the mathematical calculations mentioned in the previous section, different characters of the system were calculated and are mentioned in table 1.

Table: I. Price details of components

\begin{tabular}{|c|c|r|}
\hline Component & Material & Cost (Rs) \\
\hline Mirror film & $3 \mathrm{M} \quad$ reflecting tape & 1300 \\
\hline Mechanical structure & Steel & 6000 \\
\hline Receiver pot & Stainless steel & 730 \\
\hline PCM & $\mathrm{Mg}(\mathrm{NO} 3) 2.6 \mathrm{H} 2 \mathrm{O}$ & 400 \\
\hline Total & & 8430 \\
\hline
\end{tabular}

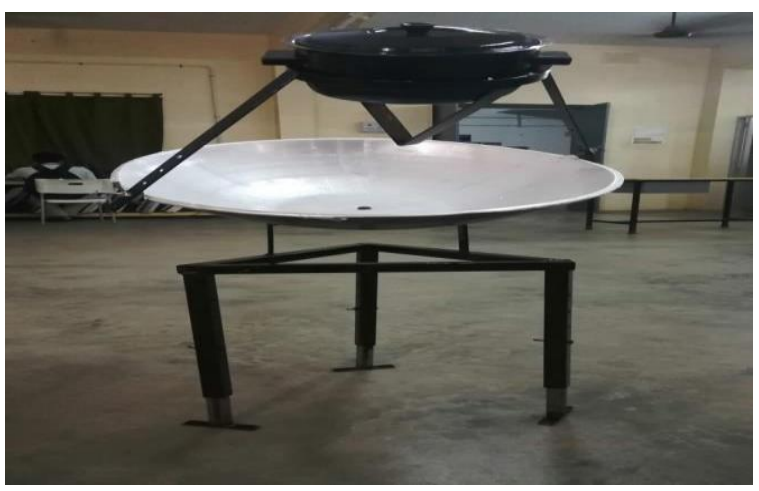

Fig. 7. Complete system of solar cooker with PCM

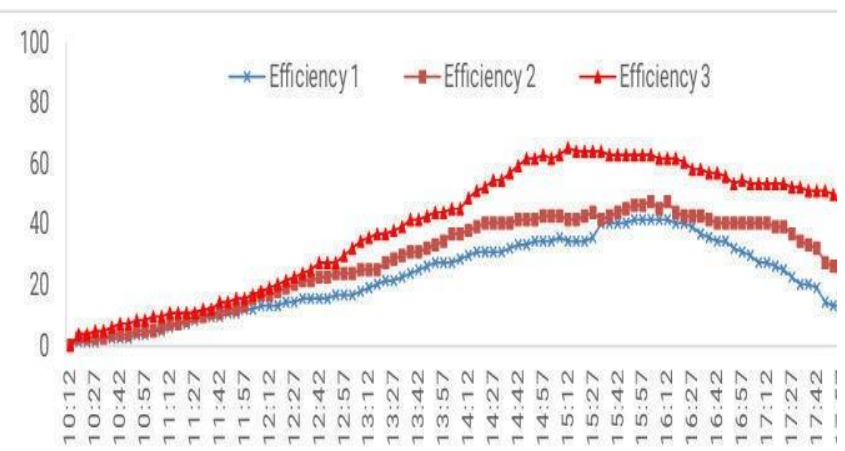

Fig. 8. Efficiency of the solar cooker

Fig. 8 represents the productiveness of the structure in different conditions. Efficiency 1,2 and 3 are the No load, with water in gap and with water in pot and PCM in gap respectively. The average efficiencies for the corresponding cases are $20 \%$.

Fig. 7 represents the complete schematic sketch of the portable solar parabolic cooker. The adjustable supports of the receiver and the system can be adjustable depending on the position of the sun throughout the day. Manual tracking of the parabolic dish is possible with the help of adjustable screw

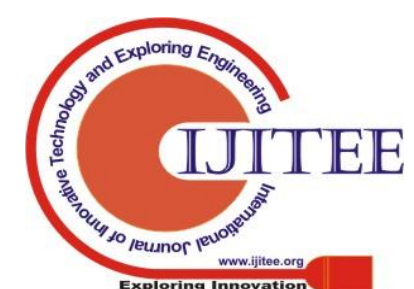


mechanism in the support stands.

Table: II. Units and values of solar boiler

\begin{tabular}{|c|c|c|c|c|c|c|c|}
\hline Parameter & $\mathbf{f}$ & $\boldsymbol{\phi}$ & $\mathbf{C}$ & $\mathbf{p}$ & $\boldsymbol{A}_{\boldsymbol{s}}$ & $\boldsymbol{A}_{\boldsymbol{a}}$ & $\boldsymbol{A}_{\boldsymbol{f}}$ \\
\hline units & $\mathrm{cm}$ & $(0)$ & & $\mathrm{cm}$ & $\mathrm{cm}^{2}$ & $\mathrm{~cm}^{2}$ & $\mathrm{~cm}^{2}$ \\
\hline value & 13 & 100 & 1 & 26 & 2588.7 & 2123 & 13.07 \\
\hline
\end{tabular}

$26 \%$ and $44 \%$ respectively. Time taken to boil 1.5 liters of water with PCM in gap is about 10 minutes

\section{CONCLUSION}

Boiling energy plays a pivotal role in the feasible management of power in both Indian and global domestic establishment. There are different options for fulfilling user needs using non-commercial and commercial resources. With the developed solar cookers, traditional fuels such as wood pellets, dung cakes and kerosene use must be reduced. The portable parabolic cooker with PCM storage was arranged and developed for the current paper. The storage material used is an inorganic PCM named as $\mathrm{Mg}(\mathrm{NO} 3) 2.6 \mathrm{H} 2 \mathrm{O}$. The focal length of the parabolic cooker is about $32 \mathrm{~cm}$ and the diameter of the parabolic dish is $52 \mathrm{~cm}$. The total cost of the system with materials available in the market is around Rs. 8500. The efficiency of the designed system is about $44 \%$ in the month of March. The time taken to boil 1.5 liters of water with PCM present in the gap of the cooking pot layers is around 10 minutes. From the results of the proposed system, it can be concluded that the designed portable parabolic boiler with PCM depository can be a good output for the fossil fuel free boiling technology.

\section{REFERENCES}

1. S. A. Kalogirou, "Solar Energy Engineering: Processes and Systems," Elsevier Science, 2013.

2. V.B. Manimaran, "Design and Implementation of Solar - Wind Combo for Hybrid Energy Application," International Journal of MC Square Scientific Research, vol.5, no.1, 2013, pp. 37-42.

3. H. P. Garg and J. Prakash, Solar energy fundamentals and applications," Tata McGraw-Hill Publishing, 2000.

4. G. Tiwari and S. Suneja, "Solar Thermal Engineering Systems," Narosa Publishing House, 1997.

5. C. Venkataraman, A. D. Sagar, G. Habib, N. Lam, and K. R. Smith, "The Indian National Initiative for Advanced Biomass

Cookstoves: The benefits of clean combustion, " Energy for Sustainable Development, vol. 14, 2010, pp. 63-72

6. I. Dinçer and M. Rosen, "Thermal energy storage: systems and applications, "2nd ed. Chichester: Wiley, 2011.

7. V. Daioglou, B. J. van Ruijven, and D. P. van Vuuren, "Model projections for household energy use in developing countries," Energy, vol. 37, 2012, pp. 601-615

8. L. F. C. Harald Mehling, "Solid liquid phase change materials," in Heat and cold storage with PCM: An up to date introduction into basics and applications," Springer, 2008.

9. G. Raam Dheep and A. Sreekumar, "Influence of nano-materials on properties of latent heat solar thermal energy storage materials- A review," Energy Conversion and Management, vol. 83, 2014, pp. 133-148.

10. S. D. Sharma, D. Buddhi, R. L. Sawhney, and A. Sharma, "Design, development and performance evaluation of a latent heat storage unit for evening cooking in a solar cooker," Energy Conversion and Management, vol. 41, 2000, pp. 1497-1508.

11. J. Aidan, "Performance Evaluation of a Parabolic Solar Dish Cooker in Yola," Nigeria vol. 6, 2014.

12. A. Herez, M. Ramadan, and M. Khaled, "Review on solar cooker systems Economic and environmental study for different Lebanese scenarios," Renewable and Sustainable Energy Reviews, vol. 81, 2018 pp. 421-432.
13. S.Siva, "Automatic Solar Tracker," International Journal of MC Square Scientific Research vol.8, no.1, 2016.

\section{AUTHORS PROFILE}

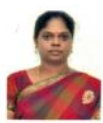

Dr. L.Chitra is an Associate Professor and Head in the department of EEE at AarupadaiVeedu Institute of Technology. She received her Bachelor Degree in Electronics and Instrumentation Engineering. She received her Master's Degree in Power Electronics and Drives in Anna University. She completed her PhD in Sathyabama Institute of Science and Technology in the field of Micro Electro Mechanical Systems for sensor design. Her research area includes MEMS, Renewable Energy, Process control, Sensors and Smart Sensors. She has published more than fifteen papers in International Conferences and Journals. She has a teaching experience of more than 18 years. She has received MNRE fund of Rs.1,50,000 for National Conference on Emerging Trends in New Renewable Energy Sources in the year 2014. She has also received a fund of Rs.1,00,000 from Unnat Bharat Abhiyan for Mobile Reverse osmosis based water purification system using Solar PV source for rural india in year 2019. She has also received a fund of Rs.50,000 from Unnat Bharat Abhiyan forDC Micro Grid based Solar PV generation to supply power to street lamp and common utilities in a village.

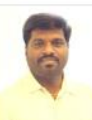

S. Prakash is an Assistant Professor (Gr-II) of Department of EEE at AarupadaiVeedu Institute of Technology. He received his B.E in Electrical and Electronics Engineering (2006) from Government college of Engineering and M.E in Power system Engineering (2008) from Annamalai University. He has more than 10 publications in the field of Power System Engineering. He is research scholar in Department of Electrical Engineering, Vinayaka Missions Research Foundation. His research interests include special Electrical Machines and Drives.

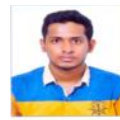

M. Anand UG Student, department of EEE, AarupadaiVeedu Institute of Technology.

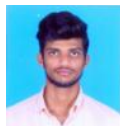

Jeffin Mathew UG Student, Department of EEE AarupadaiVeedu Institute of Technology.

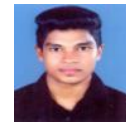

Darwin Varghese UG Student, Department of EEE, AarupadaiVeedu Institute of Technology. 